\title{
DEVELOPMENTS IN NON-WALRASIAN \\ ECONOMICS AND THE MICROECONOMIC \\ FOUNDATIONS OF MACROECONOMICS
}

\author{
By Jean-Pascal BENASSY \\ June 1980
}

$\mathrm{N}^{\circ} 8013$

To be presented at the Econometric Society world Congress, Aix-en-Provence, 1980.

Preliminary version, comments welcome. Do not quote without permission of the author. 


\title{
DEVELOPMENTS IN NON-WALRASIAN ECONOMICS
}

\section{AND THE MICROECONOMIC FOUNDATIONS OF MACROECONOMICS}

\author{
By Jean-Pascal BENASSY
}

\begin{abstract}
After the seminal contributions of Clower (1965) and Leijonhufvud (1968), (1) one has witnessed a considerable renewal of interest in non Walrasian economics as a way to provide rigorous microfoundations to macroeconomics. The basic idea behind all the models in this area is that prices may not clear the markets at all instants, and thus that adjustments can, at least partially, be carried out through quantities. Such a theme is evidently at the heart of Keynesian Economics, as Clower and Leijonhufvud pointed out. Further progress in the domain has in a large proportion been made along two lines :
\end{abstract}

The first is the construction of general microeconomic models abandoning the assumption of competitive equilibrium on all markets. A first category of these models assumes some degreo of price rigidity, and studies the associated quantity adjustments : Glustoff (1968), Drèze (1975), Benassy (1975a), (1975b), (1977), Younès (1975), Grandmont-Laroque (1976), Malinvaud-Younès (1978), Boehm-Levine (1979), Heller-Starr (1979).

(1) Early contributions in a similar direction were found in B. Hansen (1951), Patinkin (1956). 
A second category addresses the probleme of noncompetitive price formation : Negishi (1961), (1972), Benassy (1976), Hahn (1978). As we shall see in section 1.5, these two types of models can actually be synthetized.

The second line of research consists in constructing specific aggregated models to study macroeconomic themes such as unemployment or inflation : Solow-Stiglitz (1968), Younès (1970), Barro-Grossman (1971), (1974), (1976), Grossman (1971), Benassy (1973), (1974), (1978a), (1978b), Malinvaud (1977), Negishi (1978), (1979), Hildenbrand-Hildenbrand (1978), Dixit (1978), Muellbauer-Portes (1978).

We shall not in this paper make a survey of the field, but rather give a outlook on these two lines of work : a first part will present a number of Non-Walrasian Equilibrium concepts in microeconomic models, while the second part will study the role of expectations in a simple macromodel of unemployment. 


\section{NON - WALRASIAN EQUILIBRIUM CONCEPTS.}

One of the purposes for constructing new concepts of Non-Walrasian Equilibrium is to bridge the gap with Keynesian models. These usually are, at least implicitly, temporary equilibrium models with some degree of price rigidity', where quantity adjustments thus replace price adjustments to some extent : the most common IS-LM model assumes the interest rate flexible, but the price and wage level given. Other models will differ in that they assume the price level flexible, either adjusting "competitively", or, in a more truly Keynesian vein, determined in a pattern of monopolistic competition.

In order to accomodate these different formulations, we shall present successively two concepts : a concept of fix-price equilibrium (section 1.3), somehow the polar case of the General equilibrium concept, and a concept of temporary equilibrium with price makers (section 1.5) allowing flexible prices to be determined by agents internal to the economy. The role of expectations in these temporary equilibria is made precise in section 1.4. Before studying the concepts themselves, a typical Walrasian model) is presented (section 1.1) in order to underline better the specificities of non-Walrasian economics, and the common institutional framework of our models is described (section 1.2). 


\section{1. - A TYPICAL WALRASIAN EQUIIIBRIUM MODEL.}

The exchange economy considered will have $r$ goods, indexed by $h=1, \ldots, r$, and $n$ consumers-traders, indexed by $i=1, \ldots, n$. Agent $i$ has a bundle of initial resources represented by a vector $e_{i} \in R_{+}^{r}$, carries nẹt trades represented by a vector $z_{i} \in R^{r}$ with components $z_{i h}$ satisfying $e_{i}+z_{i} \geq 0$, and has a utility function over these trades $U_{i}\left(z_{i}\right)$, which we shall assume strictly concave.

For each price vector $p \in R_{+}^{r}$, agent $i$ determines his vector of net demands by maximizing utility subject to the budget constraint, i.e. :

$$
\begin{aligned}
& \text { Maximize } U_{i}\left(z_{i}\right) \cdot \text { s.t. } \\
& \left\{\begin{array}{l}
e_{i}+z_{i} \geq 0 \\
p z_{i}=0
\end{array}\right.
\end{aligned}
$$

One obtains in this way a net demand function $z_{i}(p)$, with components $z_{i h}(p)$ for each good. We should remark that this demand function is notional, in the terminology of Clower (1965), i.e. constructed under the assumption that any desired trade can be carried out.

A Walrasian equilibrium price vector $p^{*}$ will be determined by the condition that net excess demand be zero on all markets :

$$
\sum_{i=1}^{n} z_{i h}\left(p^{*}\right)=0 \quad h=1, \ldots, r
$$

Concavity assumptions on preferences are here sufficient to guarantee the existence of such an equilibrium. 


\section{2. - NON-WALRASIAN MODELS : THE INSTITUTIONAL SETTING.}

In Walrasian analysis, a transactor is assumed to be able to reach any trade on his budget line. One does not need to specify which markets (in the sens of the Walrasian trading posts) are open, or how exchange is organized on each market. When we turn to non Walrasian analysis where quantity constraints may be present, these problems become important and we turn to them now.

\subsubsection{A MONETARY ECONOMY.}

In all that follows, we shall work in a monetary economy, money being a numeraire, a medium of exchange and a store of value. Let thus be $r$ nonmonetary goods, indexed by $h=1, \ldots, r$ plus money. Let $p_{h}$ be the money price of good $h$. Money being the medium of exchange, there will be $r$ trading posts, or markets, on which each of these goods will be exchanged against money. $z_{\text {ih }}$ will thus represent the intensity of the trade of good $h$ against money, the monetary counterpart being $\mathrm{P}_{\mathrm{h}} \mathrm{z}_{\text {ih }}$. Aggregating all these partial trades, one obtains a budget constraint similar to the traditional one :

$$
p z_{i}+M_{i}=\vec{M}_{i}
$$

where $\bar{M}_{i}$ is the initial money holding of agent $i$, $M_{i}$ his final money holding. 
We should emphasize here that we do not mean that the monetary transaction structure is necessary for quantity constraints analysis, as has been wrongly understood by a few authors (1), but rather that the following analysis is the one relevant to a monetary economy. Non Walrasian analysis can be carried as well in barter, or other, frameworks, at the price of a different, and somewhat heavier formalization (cf. Benassy 1975a).

(1) Drazen (1980) is a recent and conspicuous example. 


\subsubsection{DEMANDS, TRANSACTIONS AND RATIONING SCHEMES.}

We must now make an important distinction, which by nature is not made in equilibrium models, that between demands and transactions.

Transactions, i.e. purchases and sales, are the exchanges actually, carried on a market. They must balance as an identity on each market, i.e. calling $z_{i h}^{*}$ the transaction of agent $i$ on market $h$ :

$$
\sum_{i=1}^{n} z_{i h}^{*} \equiv 0 \quad \text { for all h. }
$$

Demands and supplies in the contrary are tentative trades, signals transmitted to the market before exchange takes place. So if we denote by $\tilde{z}_{i h}$ the net effective demand of agent $i$ on market $h$, we may have :

$$
\sum_{i=1}^{n} \tilde{z}_{i h} \neq 0
$$

Each market has a particular organization, which converts possibly inconsistent demands and supplies into consistent transactions. This will be represented through a rationing scheme, i.e. a set of $n$ functions :

$$
z_{i h}^{*}=F_{i h}\left(\tilde{z}_{1 h}, \ldots, \tilde{z}_{n h}\right) \quad i=1, \ldots, n
$$

such that $\sum_{i=1}^{n} F_{i h}\left(\tilde{z}_{1 h}, \ldots, \tilde{z}_{n h}\right)=0$ for all $\tilde{z}_{1 h}, \ldots, \tilde{z}_{n h}$. We shall actually rewrite these functions under the form

$$
\begin{gathered}
z_{i h}^{*}=F_{i h}\left[\tilde{z}_{i h}, \tilde{z}_{i h}\right] \\
\text { with } \tilde{z}_{i h}=\left\{\tilde{z}_{1 h}, \ldots, \tilde{z}_{i-1, h}, \tilde{z}_{i+1, h}, \ldots, \tilde{z}_{n h}\right\} .
\end{gathered}
$$


We shall assume throughout that the rationing schemes have the following properties :

(i) $F_{i h}$ is continuous in its arguments, nondecreasing in $\tilde{z}_{i h}$.

(ii) $z_{i h}^{*} \cdot \tilde{z}_{i h} \geq 0 \quad\left|z_{i h}^{*}\right| \leq\left|\tilde{z}_{i h}\right|$

This last property is generally known as voluntary exchange.

An other often made assumption, but which we shall not need in the sequel, is that of a "frictionless" market, according to which traders on the "short" side realize their desired trades :

$$
\left(\sum_{j=1}^{n} \tilde{z}_{j h}\right) \cdot \tilde{z}_{i h} \leq 0 \Longrightarrow z_{i h}^{*}=\tilde{z}_{i h}
$$

Examples of rationing schemes are numerous : uniform rationing, proportional rationing, queueing, priority systems, etc ... To each of these will be associated a particular set of functions $F_{i h}$. 


\subsubsection{MANIPULATION, QULANTITY SIGNALS.}

We introduce here a classification which will appear important in what follows, that between manipulable and nonmanipulable rationing schemes. The difference is well seen in figure 1, where we plotted the relation between $z_{i h}^{*}$ and $\tilde{z}_{i h}, \tilde{z}_{i h}$ being held constant. Intuitively, a scheme is nonmanipulable if each trader faces upper and lower bounds in his trades, which he cannot manipulate. A scheme is manipulable if a trader can, even if he is rationed, increase his transaction by increasing his demand.

The queueing process is nonmanipulable, the proportional rationing scheme is manipulable. Mathematically, we shall say that a rationing scheme is nonmanipulable if:

$$
F_{i h}\left(\tilde{z}_{i h}, \tilde{z}_{i h}\right]= \begin{cases}\min \left[\tilde{z}_{i h}, \bar{G}_{i h}\left[\tilde{z}_{i h}\right]\right] & \text { if } \tilde{z}_{i h} \geq 0 \\ \max \left[\tilde{z}_{i h}, \underline{G}_{i h}\left[\tilde{z}_{i h}\right]\right] & \text { if } \tilde{z}_{i h} \leq 0\end{cases}
$$

where :

$$
\begin{aligned}
& \bar{G}_{i h}\left(\tilde{Z}_{i h}\right)=\max \left\{\zeta \mid F_{i h}\left(\zeta, \tilde{Z}_{i h}\right)=\zeta\right\} \\
& \underline{G}_{i h}\left(\tilde{Z}_{i h}\right)=\min \left\{\zeta \mid F_{i h}\left(\zeta, \tilde{Z}_{i h}\right)=\zeta\right\}
\end{aligned}
$$

Otherwise the scheme is manipulable. Manipulable schemes usually lead to a process of overbidding which may prevent the existence of an equilibrium (Benassy 1977a). In what follows we shall thus concentrate on nonmanipulable schemes, which can be represented shortly as : 


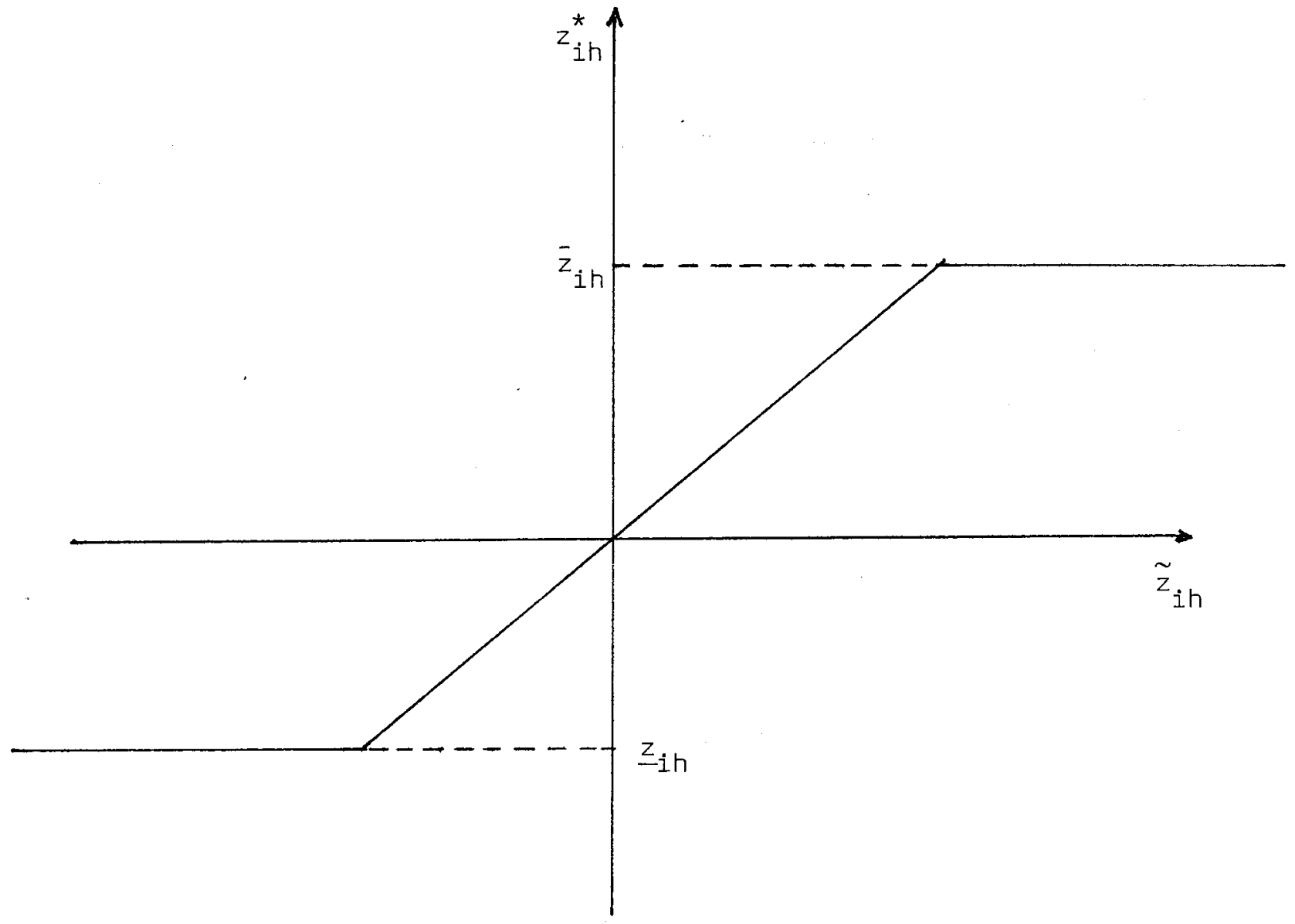

Nonmanipulable

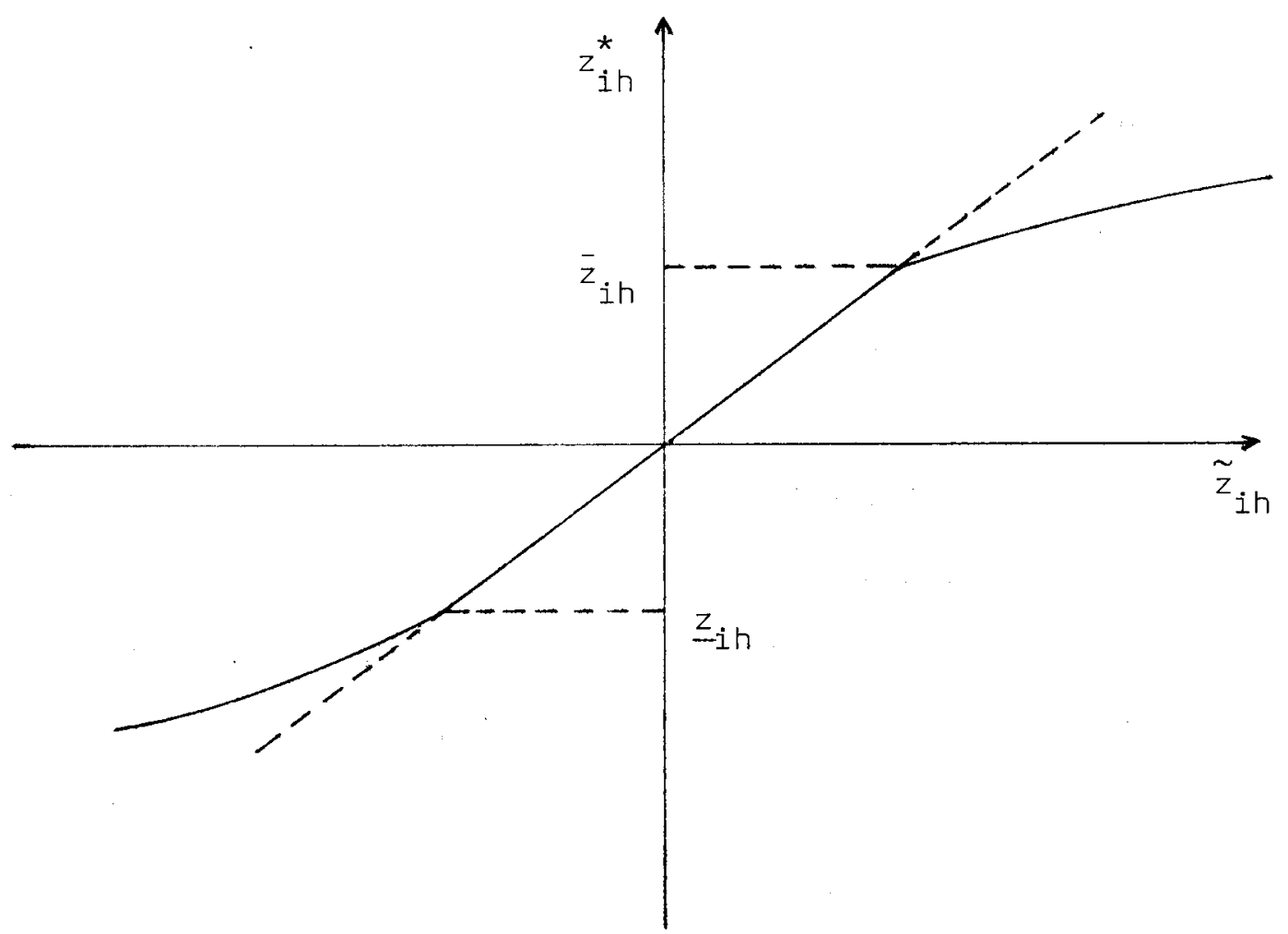

Manipulable

Fig. 1 


$$
z_{i h}^{*}= \begin{cases}\min \left(\tilde{z}_{i h}, \bar{z}_{i h}\right) & \tilde{z}_{i h} \geq 0 \\ \max \left(\tilde{z}_{i h}, z_{i h}\right) & \tilde{z}_{i h} \leq 0\end{cases}
$$

$$
\begin{aligned}
& \text { or } z_{i h}^{*}=\min \left[\bar{z}_{i h}, \max \left(\tilde{z}_{i h}, \underline{z}_{i h}\right]\right] \\
& \text { with } \quad \bar{z}_{i h}=\bar{G}_{i h}\left(\tilde{z}_{i h}\right) \quad \underline{z}_{i h}=\underline{G}_{i h}\left(\tilde{z}_{i h}\right)
\end{aligned}
$$

$\bar{z}_{i h}$ and $\underline{z}_{i h}$ will be called the perceived constraints. 


\section{3. - FIX-PRICE EQUILIBRIA ${ }^{(1)}$.}

We shall first study the "polar" case of Walrasian analysis, by assuming that all prices are given in the period of analysis, a formalization of Hicks' fix-price method (Hicks 1965).

\subsubsection{MARKETS AND AGENTS.}

We shall thus have a monetary exchange economy with I markets $(h=1, \ldots, r)$. The price $p_{h}$ on each market will be given. There will be $n$ agents $(i=1, \ldots, n)$. Agent $i$ has an initial endowment of goods $e_{i} \in R_{+}^{r}$, of money $\bar{M}_{i} \geq 0$. He has an indirect utility function. $v_{i}\left(z_{i}, M_{i}, \sigma_{i}\right)$, where $\sigma_{i}=\left\{p, \bar{z}_{i}, \underline{z}_{i}\right\}$ is the set of price and quantity signals received by $i$. The derivation of $V_{i}$ from more basic data will be seen in the next section. We shall assume that $V_{i}$ is strictly concave in $z_{i}$, concave in $M_{i}$.

The fix-price equilibrium concept will involve three types of quantities : effective demands $\left(\tilde{z}_{i h}\right)$, transactions $\left(z_{i h}^{*}\right)$, perceived constraints $\left(\bar{z}_{i h}, \underline{z}_{i h}\right)$. We have already seen how transactions and perceived constraints were derived from effective demands :

$$
\begin{aligned}
& z_{i h}^{*}=F_{i h}\left(\tilde{z}_{i h}, \tilde{z}_{i h}\right) \\
& \bar{z}_{i h}=\bar{G}_{i h}\left(\tilde{z}_{i h}\right) \\
& \underline{z}_{i h}=\underline{G}_{i h}\left(\tilde{z}_{i h}\right)
\end{aligned}
$$

(1) The material in this section is borrowed from Benassy (1975b), (1977). Numerous alternative formalizations of fix-price equilibria have been given, starting with the seminal paper of Drèze (1975). Let us quote also Younès (1975), Boehm-Levine (1979), Heller Starr (1979). For concepts in nonmonetary economies, see Benassy (1975a), Malinvaud-Younès (1978). 
There remains thus only to study the determination of effective demands themselves, a task to which we turn now.

\subsubsection{EFFECTIVE DEMANDS.}

- Consider a trader i facing a price vector $p$ and vectors of quantity constraints $\bar{z}_{i}$ and $\underline{z}_{i}$. He will choose the vector of effective demands so as to yield the best transaction possible. Let us call $\zeta_{i}^{*}\left(p, \bar{z}_{i}, \underline{z}_{i}\right)$ this best transaction. It will be solution of the following program :

$$
\begin{aligned}
& \text { Maximize } v_{i}\left(z_{i}, M_{i}, \sigma_{i}\right) \quad \text { s.t. } \\
& \begin{cases}e_{i}+z_{i} \geq 0 \quad M_{i} \geq 0 \\
p z_{i}+M_{i}=\bar{M}_{i} \\
z_{i h} \leq z_{i h} \leq \bar{z}_{i h} \quad h=1, \ldots, r .\end{cases}
\end{aligned}
$$

However we are here interested in effective demands. The transaction $z_{i h}$ resulting from effective demand $\tilde{z}_{i h}$ on market $h$, is :

$$
z_{i h}=\min \left[\bar{z}_{i h}, \max \left(\tilde{z}_{i h}, \underline{z}_{i h}\right)\right]
$$

The vector of effective demands will be chosen so as to yield the best possible transaction, i.e. it will be solution of the following program : 


$$
\begin{aligned}
& \operatorname{Max} v_{i}\left(z_{i}, M_{i}, \sigma_{i}\right) \quad \text { s.t. } \\
& \left\{\begin{array}{l}
e_{i}+z_{i} \geq 0 \quad M_{i} \geq 0 \\
p z_{i}+M_{i}=\bar{M}_{i} \\
z_{i h}=\min \left[\bar{z}_{i h}, \max \left(\tilde{z}_{i h}, \underline{z}_{i h}\right)\right] \quad h=1, \ldots, r .
\end{array}\right.
\end{aligned}
$$

Unfortunately, even with $V_{i}$ strictly concave in $z_{i}$, the set of solutions of the above program is generally multivalued. Rather to work with a correspondence, we shall make a selection in the solution set and define an effective demand function; formally, the effective demand function on market $h$, which we shall denote functionally $\tilde{\zeta}_{i h}\left(p, \bar{z}_{i}, \underline{z}_{i}\right)$, will be the h-th component of the vector solution of the following program :

$$
\begin{aligned}
& \text { Maximize } v_{i}\left(z_{i}, M_{i}, \sigma_{i}\right) \quad \text { s.t. } \\
& \left\{\begin{array}{l}
p_{i}+M_{i}=\bar{M}_{i} \\
e_{i}+z_{i} \geq 0 \quad M_{i} \geq 0 \\
\underline{z}_{i k} \leq z_{i k} \leq \bar{z}_{i k}
\end{array} \quad \text { for all } k \neq n\right.
\end{aligned}
$$

In words effective demand corresponds to the utility maximizing trade, taking into account perceived constraints on the other markets. It is easily shown that under strict concavity this function belongs to the above correspondence. Without strict concavity, one should revert to the more general definition (Benassy 1977a). 


\subsubsection{FIX-PRICE EQUTLIBRIUM.}

We are now ready to give the definition of a fixprice equilibrium (or K-equilibrium) associated to a price vector $p$ as a set of effective demands, transactions and perceived constraints such that :

(1) $z_{i h}^{*}=F_{i h}\left(\tilde{z}_{i h}, \tilde{z}_{i h}\right) . \quad$ for all $i, h$

(2) $\bar{z}_{i h}=\bar{G}_{i h}\left(\tilde{z}_{i h}\right) \quad$ for all $i$, h

$$
\underline{z}_{i h}=\underline{G}_{i h}\left(\tilde{Z}_{i h}\right)
$$

(3) $\quad \tilde{z}_{i h}=\tilde{\zeta}_{i h}\left(p, \bar{z}_{i}, \underline{z}_{i}\right) \quad$ for all $i, h$

(4) $\quad z_{i h}^{*}=\zeta_{i h}^{*}\left(p, \bar{z}_{i}, \underline{z}_{i}\right) \quad$ for all $i, h$

Note that condition (4) is redundant in view of the definition of effective demand. It is included here as a reminder. Existence of a fix-price equilibrium is easily proved under strict concavity of $v_{i}$ in $z_{i}$. If the rationing scheme on market $h$ is frictionless, then agents on one side of the market only will perceive binding constraints, a property central to Drèze's (1975) concept. 


\section{4. - TEMPORARY KEYNESIAN EQUILIBRIUM (1).}

In the previous sections we assumed that each agent was endowed with an indirect utility function $v_{i}\left(z_{i}, M_{i}, \sigma_{i}\right)$, having only current trades, money holdings and signals as arguments. We shall now show how this can be derived from a multiperiod optimization program taking expectations about future prices and quantities into account. Accordingly, the current equilibrium will have the character of a temporary equilibrium. Our construction will at the same time provide a formalization of money's role as a store of value in situations of possible disequilibrium.

\subsubsection{MARKETS AND AGENTS.}

We shall consider here a two period exchange economy (the argument would extend without problem to any finite number of periods). In the first period there are markets for $r_{1}$ nonmonetary goods, for $r_{2}$ in the second period. Money is assumed to be the only store of value between the two periods.

There are $n$ treders, indexed by $i=1, \ldots, n$. Trader $i$ has initial endowments $e_{i 1} \in R_{+}^{{ }^{r}}$ and $e_{i 2} \in R_{+}{ }^{r_{2}}$ in the first and second periods respectively. His net trades $z_{i 1} \in R^{r_{1}}$ and $z_{i 2} \in R^{{ }^{2}}$ must satisfy :

$$
e_{i 1}+z_{i 1} \geq 0 \quad e_{i 2}+z_{i 2} \geq 0
$$

(1) This section is based on Benassy (1975b). 
At the outset of the first period, agent $i$ has an initial quantity of money $\bar{M}_{i}$. He will transfer to the second period a quantity $M_{i}$ given by :

$$
p z_{i 1}+M_{i}=\bar{M}_{i}
$$

Transactions of the second period will have to satisfy:

$$
p_{2} z_{i 2} \leq M_{i}
$$

We shall assume that each agent ranks his possible transaction streams (current and expected) according to a utility function $U_{i}\left(z_{i 1}, z_{i 2}\right)$.

Finally each agent holds expectations about the price and quantity signals he will face in the second period, which we shall denote $\sigma_{i 2}$ :

$$
\sigma_{i 2}=\left\{p_{2}, \bar{z}_{i 2}, \underline{z}_{i 2}\right\}
$$

We shall assume that expected price-quantity signals depend upon current signals $\sigma_{i 1}$ (and past signals which are a datum here), so that we shall write

$$
\sigma_{i 2}=\psi_{i}\left(\sigma_{i 1}\right)
$$

\subsubsection{THE INDIRECT UTILITY OF MONEY.}

Assume that agent $i$ has traded $z_{i 1}$ in the first period, and transferred. a quantity of money $M_{i}$. With given price-quantity expectations $\sigma_{i 2}$, his expected transaction vector in the second period should be the one maximizing his utility, subject to the budget constraint and all quantity constraints, i.e. it should be solution of : 


$$
\begin{aligned}
& \left.\operatorname{Max}_{i} u_{i 1}, z_{i 2}\right) \quad \text { s.t. } \\
& \left\{\begin{array}{l}
p_{2} z_{i 2} \leq M_{i} \\
e_{i 2}+z_{i 2} \geq 0 \\
z_{i 2} \leq z_{i 2} \leq \bar{z}_{i 2}
\end{array}\right.
\end{aligned}
$$

Let us write the vector solution of this program as :

$z_{i 2}^{\star}\left(z_{i 1}, M_{i}, \sigma_{i 2}\right)$

Now we can rewrite the level of utility, as expected from the first period, as :

$$
\begin{aligned}
u_{i}\left[z_{i 1}, z_{i 2}^{*}\left(z_{i 1}, M_{i}, \sigma_{i 2}\right]\right] & =u_{i}^{*}\left(z_{i 1}, M_{i}, \sigma_{i 2}\right)= \\
u_{i}^{*}\left[z_{i 1}, M_{i}, \psi_{i}\left(\sigma_{i 1}\right)\right] & =v_{i}\left(z_{i 1}, M_{i}, \sigma_{i 1}\right)
\end{aligned}
$$

This indirect utility function has now current trades and money holdings as arguments. It also depends upon current price and quantity signals, through their influence on expected price and quantity constraints.

\subsubsection{TEMPORARY FIX-PRICE EQUILIBRIUM.}

We can now suppress the index 1 of the current periad. We have thus current "fix-price" markets. There are $n$ traders indexed by $i=1, \ldots$ Each has an endowment $\left(e_{i}, \bar{M}_{i}\right)$ and an indirect utility function $v_{i}\left(z_{i}, M_{i}, \sigma_{i}\right)$. The structure is thus exactly the same as that of section 1.3. above. The existence of an equilibrium can be praved, provided the function $U_{i}$ is strictly concave in its arguments. 


\section{5. - TEMPORARY EQUILIBRTUM WITH PRICE MAKERS}

(1)

Obviously, fixprice models are only a first step, and we must now study models where at least some prices are flexible. Besides "auctioneer" mechanisms, two types of price making arrangements can be envisioned : the price may be set unilaterally by price makers on one side of the market, or may be bargained between the two sides. In order to avoid game-theoretic complications, we shall study only the first arrangement.

In such a setting, price makers change the price so as to "manipulate" the quantity constraints they face. An equilibrium will be reached when price makers are satisfied with the price-quantity combination they have obtained. Price makers behave thus very much like imperfect competitors, and the concept of equilibrium we will have is in line with the pioneering article of Negishi (1961). It generalizes it in allowing some markets to have rigid prices, while the others adjust in this imperfectly competitive manner.

\subsubsection{PERCEIVED DEMAND CURVES.}

Dur Economy will consist as before of exchangers, indexed by

$i=1, \ldots, n$; trader $i$ has endowments $\left(e_{i}, \bar{M}_{i}\right)$ and a utility function $v_{i}\left(z_{i}, M_{i}, \sigma_{i}\right)$. We shall assume that agent $i$ controls the prices of goods $h \in H_{i}$, with :

$$
H_{i} \cap H_{j}=\{\phi\} \quad i \neq j
$$

(1) This section is based on Benassy (1976). 
There may be a set of goods $H_{0}$ whose prices are fixed land thus not controlled by anybody). We shall call $p_{i}$ the subvector of prices controlled by agent $i$.

Each price making agent has a perceived demand curve (resp. supply curve) relating the maximum quantities he can sell (resp. buy) to the price he sets. We shall denote them, the usual sign convention :

$\underline{z}_{i h}\left(p_{i} \mid \sigma_{i}\right)$ for the perceived demand curve $\bar{z}_{i h}\left(p_{i} \mid \sigma_{i}\right)$ for the perceived supply curve

Perceived demand and supply curves must be consistent with the signals received in the sense that, if trader $i$ has observed a signal $\sigma_{i}=\left\{\bar{p}, \bar{z}_{i}, \underline{z}_{i}\right\}$, we must have :

$$
\begin{aligned}
& \bar{z}_{i h}\left(\bar{p}_{i} \mid \bar{p}, \bar{z}_{i}, \underline{z}_{i}\right)=\bar{z}_{i h} \\
& \underline{z}_{i h}\left(\bar{p}_{i} \mid \bar{p}, \bar{z}_{i}, \underline{z}_{i}\right)=\underline{z}_{i h}
\end{aligned}
$$

i.e. the perceived curves must "go through" the observed point

\subsubsection{PRICE MAKING.}

A price-maker will choose a price vector so as to maximize his utility subject to the trades which he perceives as possible. Assume that he receives price and quantity signals $\sigma_{i}=\left\{\bar{p}, \bar{z}_{i}, \underline{z}_{i}\right\}$. He will choose his vector of prices $p_{i}$ so as to : 


$$
\begin{aligned}
& \text { Maximize } v_{i}\left(z_{i}, M_{i}, \sigma_{i}\right) \quad \text { s.t. } \\
& \begin{cases}p_{i}+M_{i}=\bar{M}_{i} \\
e_{i}+z_{i} \geq 0 \quad M_{i} \geq 0 \\
p_{h}=\bar{p}_{h} \quad \underline{z}_{i h} \leq z_{i h} \leq \bar{z}_{i h} \\
\underline{z}_{i h}\left(p_{i}, \sigma_{i}\right) \leq z_{i h} \leq \bar{z}_{i h}\left(p_{i}, \sigma_{i}\right) & h \in H_{i}\end{cases}
\end{aligned}
$$

We shall denote the optimal price functionally as :

$$
\rho_{i}^{*}\left(\sigma_{i}\right)=\rho_{i}^{*}\left(\bar{p}, \bar{z}_{i}, \underline{z}_{i}\right)
$$

\subsubsection{EQUILIBRIUM WITH PRICE-MAKERS.}

Intuitively one can define an equilibrium with price makers as a fix-price. equilibrium such that no price maker has any incentive to change his prices. We shall make this formal through the following :

\section{Definition}

An equilibrium with price makers is defined by a price vector $p^{*}$, net trades $z_{i}^{*}$, effective demands $\tilde{z}_{i}$, perceived constraints $\bar{z}_{i}$ and $\underline{z}_{i}$, such that :

(1) $\left(z_{i}^{*}\right),\left(\tilde{z}_{i}\right),\left(\bar{z}_{i}, \underline{z}_{i}\right)$ are a fixprice equilibrium with respect to $p^{*}$

(2) $p_{i}^{*}=P_{i}^{*}\left(p^{*}, \bar{z}_{i}, \underline{z}_{i}\right)$ 
The temporary equilibrium so obtained will depend upon the values of prices which are fixed. The existence of such an equilibrium can be proved only if the functions $\mathcal{P}_{i}^{*}$ satisfy some boundedness assumptions. These may be jeopardized by some patterns of expectation formation, a difficulty already known in studies of competitive temporary equilibrium (Grandmont 1974). 


\section{UNEMPLOYMENT AND EXPECTATIONS,}

We want to construct here a simple macromodel using the methods described above, and notably the concept of fix-price equilibrium, to study the problem of the nature of unemployment. There is already a fairly developed, body of literature along this line, consisting mainly of the seminal work of Barro-Grossman (1971) (1976), and its different adaptations : Benassy (1974) (1978a), Malinvaud (1977), Hildenbrand-Hildenbrand (1978), Muellbauer-Portes (1978).

Our emphasis here will be on showing in a very explicit manner the effects of expectations on the current equilibrium and the nature of unemployment ${ }^{(1)}$. We shall see in particular that the traditional association between the type of unemployment (Classical or Keynesian in Malinvaud's terminology), and specific patterns of excess demands and supplies, is not valid anymore, an issue somewhat overlooked in other works.

Our exposition will proceed as follows : we shall first construct a simple fix-price model adapted from Barro-Grossman, where firms do not hold any stocks (section 2.1). Equilibria and types of unemployment will be described in this simple model (section 2.2). We shall then extend the model by allowing the firm to hold some stocks (section 2.3). The different types of equilibria will be studied for this model (section 2.4), and their relation to the firm's expectations described (section 2.5).

(1) A similar question is addressed, though in a different way, by NearyStiglitz (1980). 


\section{1. - THE MODEL WITHOUT STOCKS : PRESENTATION.}

\subsubsection{MARKETS AND AGENTS.}

We shall consider here a simple monetary economy : there are three representative economic agents : Household, firm and government, and three economic goods, output, labor and money. Accordingly there are two current markets : one on which output is exchanged against money at the price $\mathrm{P}$, one on which labor is exchanged against money at the wage $w$. The Household demands output and supplies labor, the firm demands labor and supplies output, the government demands some output. On each market, transactions realized are assumed to be the minimum of supply and demand. In what follows we shall be interested in the determinants of the current level of employment $e^{*}$ and national income $y^{*}$. Before that, we shall describe in more detail the agents and their behavior.

\subsubsection{THE FIRM.}

The representative firm has a short run production function

$$
q=F(\ell)
$$

with the traditional properties :

$$
F(0)=0 \quad F^{\prime}(l)>0 \quad F^{\prime \prime}(l)<0
$$

With no inventories, production will be equal to sales y in equilibrium. The firm attempts to maximize profits $\pi=p y-w e$ under the constraint $y \leq q$. These profits are entirely distributed to the Household. 


\subsubsection{THE HOUSEHOLD.}

The Household will be assumed to have a fixed supply of labor $\ell_{0}$. Its effective demand for goods will be described through a consumption function :

$$
\tilde{c}=c(y, \bar{M}, p, \tau)
$$

Where $\bar{M}$ is the initial holding of money of the household, and $\tau$ the tax rate at which his income is taxed. We shall assume $0<C_{y}^{\prime}<1$ $C_{\bar{M}}^{\prime}>0 C_{P}^{\prime}<0 C_{\tau}^{\prime}<0$. This consumption function is derived through the maximization of an indirect utility function subject to the budget constraint under a given income $y$ :

$$
\begin{array}{ll} 
& \operatorname{Max} V(c, M, P, y\} \\
\text { s.t. } & \quad p c+M=\bar{M}+(1-\tau) y
\end{array}
$$

The indirect utility function itself comes from an intertemporal utility maximization program, as seen above in section 1.4, where expected future incomes and prices depend upon the current one.

As an example, we shall sometimes use the indirect utility function :

$$
\alpha \log c+(1-\alpha) \log M / p
$$

Yielding a linear consumption function :

$$
\tilde{c}=\alpha\left[\frac{\bar{M}}{p}+(1-\tau) y\right]
$$




\subsubsection{GOVERNMENT.}

The Government taxes income at the rate $\tau$, and expresses an effective demand for output equal to $\tilde{g}$. Actual purchases will be noted $g^{*}$.

\subsubsection{EFFECTIVE DEMAND FOR LABOR.}

An important element in determining whether unemployment is of Classical or Keynesian type is the form of the effective demand for labor.

Let us call $\bar{y}$ the quantity constraint on sales that the firm faces ( $\bar{y}$ is actually equal to $\tilde{c}+\tilde{g}$, i.e. the total demand for output). Then the effective demand for labor $\tilde{l}^{d}$ will be given by the following program :

$$
\begin{gathered}
\text { Max py }-w \ell \\
\left\{\begin{array}{l}
y \leq q=F(\ell) \\
y \leq \bar{y}=\tilde{c}+\tilde{g}
\end{array}\right.
\end{gathered}
$$

which yields :

$$
\tilde{l}^{d}=\min \left\{F^{,-1}\left(\frac{w}{p}\right), F^{-1}(\bar{y})\right\}
$$

We see that the demand for labor has a dual nature : "Classical" if the firm is not constrained on the goods market, "Keynesian" if it is. 


\section{2. - THE DIFFERENT REGIONS.}

Anticipating upon what follows, we shall see that there are in this simple model three types of fix-price equilibria, according to the values of the parameters $p, w, \bar{M}, \tilde{g}$ and $\tau$.

- Clạssical unemployment, with excess supply of labor and excess demand of goods $[1]$.

- Keynesian unemployment, with excess supply of labor and goods.

- Repressed inflation with excess demand of labor and goods.

Because of the absence of stocks the fourth "possibility" (excess supply of goods, excess demand of labor) reduces to a degenerate case, at the limit between the two last ones. Also we should note that the association of excess demand (resp. supply) of goods to classical (resp. Keynesian) unemployment, is valid only in this simplified model.

We shall now try to determine the level of employment and production in each of these cases, then determine for which values of the parameters they are relevant.

\subsubsection{KEYNESIAN UNEMPLOYMENT.}

This case corresponds to the traditional situation of excess supply on the two markets. National income will be equal to the aggregate demand for goods, i.e. be solution of :

$$
y=\tilde{c}+\tilde{g}=c(y, \bar{M}, p, \tau)+\tilde{g}
$$

(1) Actually one should say "demand determined transactions" instead of excess supply, "supply determined transactions" instead of excess demand. 
Let us $\operatorname{call} y_{k}(\bar{M}, P, \tilde{g}, \tau)$ the solution to this equation

$$
y^{*}=y_{k}(\bar{M}, P, \tilde{g}, \tau)
$$

This is a traditional Keynesian multiplier formula with :

$$
\frac{\partial y^{*}}{\partial \tilde{g}}=\frac{1}{1-c_{y}^{\prime}}>1
$$

Employment $\ell^{*}$ is equal to $F^{-1}\left(y_{k}\right)$ and consumption $c^{*}$ to $y_{k}-\tilde{g}$. We can remark that consumption is an increasing function of $\tilde{g}$ as :

$$
\frac{\partial c^{*}}{\partial \tilde{g}}=\frac{\partial y_{k}}{\partial \tilde{g}}-1=\frac{c_{y}^{\prime}}{1-c_{y}^{\prime}}
$$

For example if $\tilde{c}=\alpha\left[\frac{\bar{M}}{p}+(1-\tau)\right.$ y $]:$

$$
y_{k}=\frac{1}{1-\alpha(1-\tau)}\left[\frac{\alpha \bar{M}}{P}+\tilde{g}\right] \text { and } c^{*}=\frac{1}{1-\alpha(1-\tau)}\left[\frac{\alpha \bar{M}}{P}+\alpha(1-\tau) \tilde{g}\right]
$$

\subsubsection{CLASSICAL UNEMPLOYMENT.}

As hinted above, this is the case of excess supply on the labor market, excess demand on the goods market. The firm is thus on the "short" side of both markets, and will be able to realize its unconstrained "neoclassical" employment-production plan. The corresponding values of employment and income, $\ell^{*}$ and $y^{*}$, will thus be :

$$
\begin{aligned}
& \ell^{*}=F^{\prime-1}\left(\frac{w}{p}\right) \\
& y^{*}=F\left[F^{-1}\left(\frac{w}{p}\right)\right]
\end{aligned}
$$


Since consumption and government purchases add up to production, private consumption will be given by lassuming government has priority in the allocation of goods] :

$$
c^{*}=y^{*}-\min \left(y^{*}, \tilde{g}\right)
$$

We see here that private consumption is inversely related to government purchases.

The reason why unemployment will be called "classical" is quite clear, since there is excess supply of labor, and the demand for labor has the "classical" form. An increase in prices, or a decrease in wages, would reduce the level of unemployment. Increasing government spending would have no effect however but reducing private consumption, and increasing the excess demand for goods.

\subsubsection{REPRESSED INFLATION.}

We are here in a situation of excess demand on the two markets. Since the household is on the short side on the labor market, the level of employment will be equal to the inelastic labor supply $l_{0}$. Accordingly production and national income will be equal to full-employment production $F\left(\ell_{0}\right)$

$$
\left\{\begin{array}{l}
e^{*}=l_{0} \\
y^{*}=y_{0}=F\left(l_{0}\right)
\end{array}\right.
$$

Assuming again that government is served in priority on the goods market, private consumption is equal to :

$$
c^{*}=y_{0}-\min \left(y_{0}, \tilde{g}\right)
$$

and varies thus inversely with government demand. 


\subsubsection{DETERMINATION OF THE REGIME.}

In the three above combinations of excess demands and supplies, we determined the expression of the employment level $\ell^{*}$ and sales $y$ * There remains now to determine for which values of the parameters we shall be in any of these three cases (1).

In Equilibrium, the transactions of each agent are the "best" with respect to his criterion, taking account of all the constraints the faces (this property was seen above in section 1.3). In particular, the transactions of the firm should maximize its profits, subject to all constraints. This means that $e^{*}, y^{*}$ and $q^{*}$ are solution of :

$$
\begin{aligned}
& \text { Max py }-w \ell \\
& \left\{\begin{array}{l}
y \leq q=F[\ell] \\
\ell \leq \ell_{0} \\
y \leq \bar{y}=\tilde{c}+\tilde{g}
\end{array}\right.
\end{aligned}
$$

But, since $\tilde{c}=C(y, \bar{M}, p, \tau), y \leq \tilde{c}+\tilde{g}$ is equivalent to $y \leq y_{k}(\bar{M}, p, \tilde{g}, \tau)$, so that the above program can be rewritten as :

$$
\begin{aligned}
& \text { Max py }-w \ell \\
& \left\{\begin{array}{l}
y \leq q=F(\ell) \\
\ell \leq \ell_{0} \\
y \leq y_{k}
\end{array}\right.
\end{aligned}
$$

(1) The method we use here was suggested by P. Michel. 
whose solution is :

$$
\begin{aligned}
& e^{*}=\min \left\{F^{-1}\left(y_{k}\right), F^{\prime-1}\left(\frac{w}{p}\right), \ell_{0}\right\} \\
& y^{*}=\min \left\{y_{k}, F\left[F^{\prime-1}\left(\frac{w}{p}\right)\right], F\left(l_{0}\right)\right\}
\end{aligned}
$$

- On this we see also quite evidently that the rigid relation between employment and sales, due to the absence of stocks, prevents that the firm be constrained on both markets, and thus suppresses the potential "fourth case" where the firm would be on the "long side" of both markets.

Rewriting one of the two above "switching" conditions in function of the "exogenous" variables of the model, we obtain :

$$
y^{*}=\min \left\{y_{k}(\bar{M}, P, g, \tau), F\left[F^{\prime-1}\left(\frac{w}{p}\right)\right], y_{0}\right\}
$$

We can classify the regions according to the values of two fundamental parameters : the real wage $w / p$ and the "Keynesian" level of income $y_{k}(\bar{M}, p, g, \tau)$ (Figure 2$)$. Their equilibrium values are respectively $F^{\prime}\left(l_{0}\right)$ and $y_{0}$

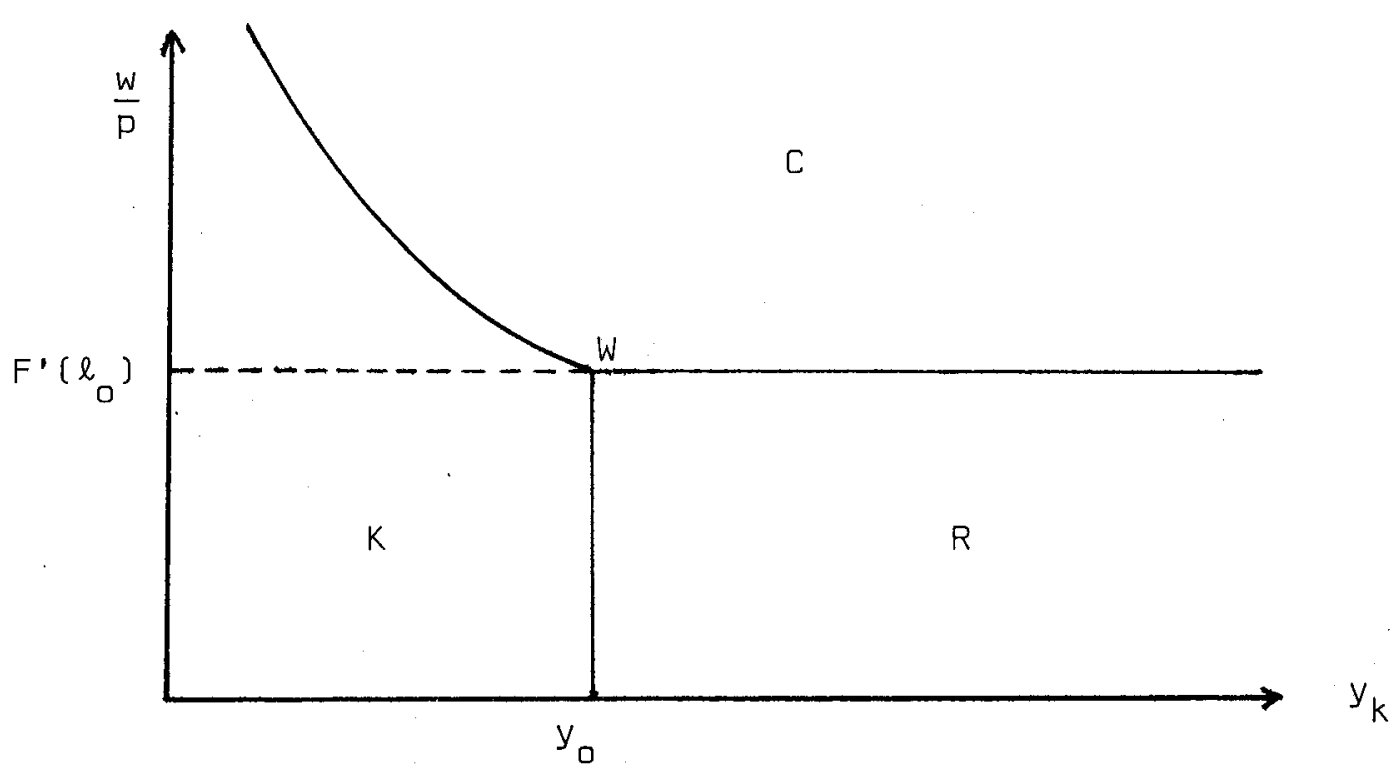


A few points are of particular interest : point $W$ is of course the short-run walrasian equilibrium, while points on the boundary between the keynesian and classical regions correspond to the "textbook keynesian" model where prices "clear" the goods market.

These regions can alternatively be depicted in the price-wage space, holding $\bar{M}, \tilde{g}$ and $\tau$ constant $\left(p^{*}\right.$ and $w^{*}$ are the short-run equilibrium price and wage)

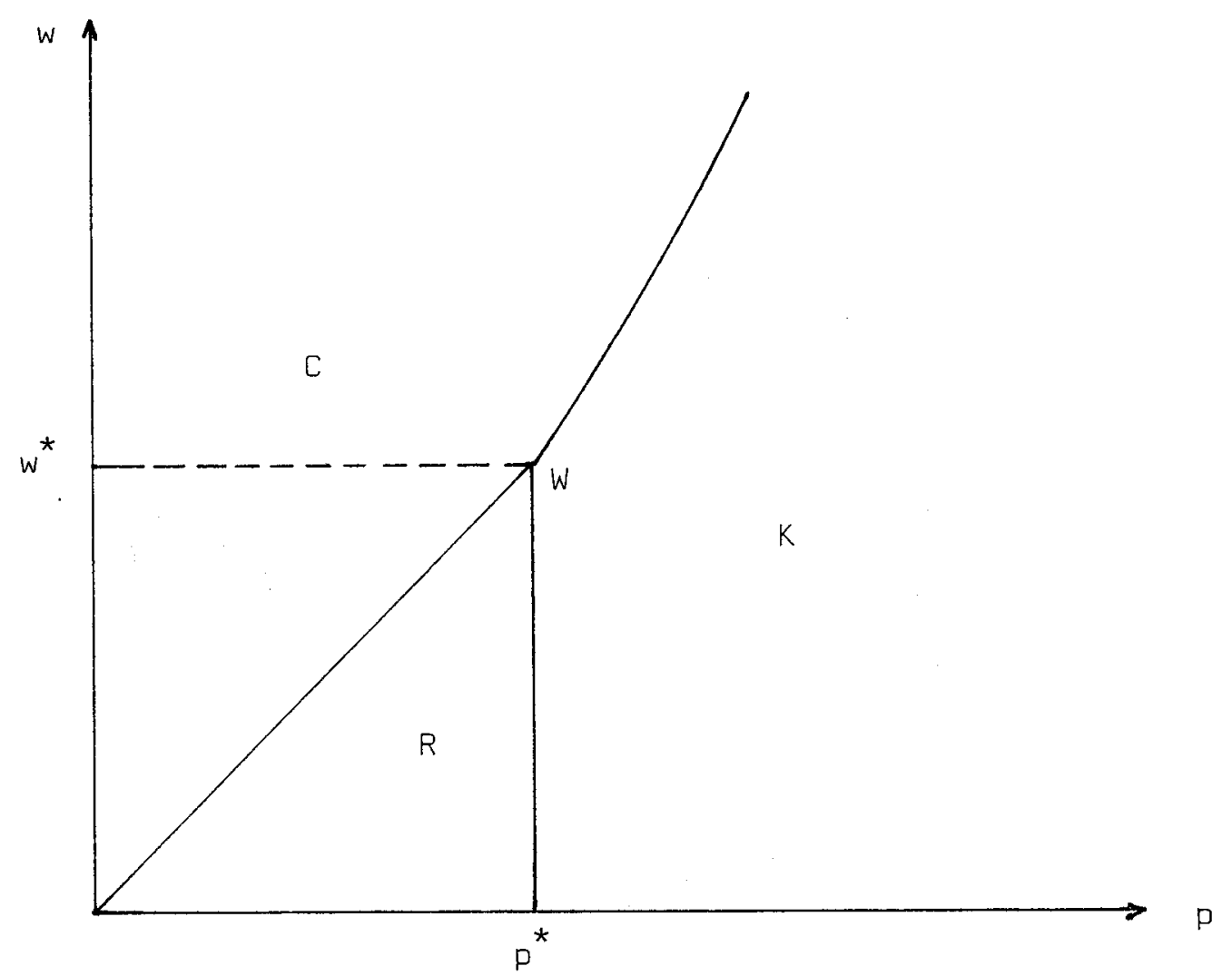

Fig. 3 


\section{3. - STOCKS AND EXPECTATIONS.}

To the very simplified model considered above, we shall now add the possibility of holding inventories for the firm. We shall also consider how expectations influence current equilibrium. Quite a number of results will be drawn from this exercise :

- First we shall see that the occurrence of full employment, classical or Keynesian unemployment, does not depend only upon current or expected prices, but very much upon quantity expectations,

- Second our model will exhibit the "fourth" region of excess demand for labor, excess supply of goods,

- Third we will see that the types of unemployment CClassical, Keynesian), do not coincide necessarily with specific combinations of excess demands ans supplies. For example Classical unemployment may occur with excess demand, or excess supply of goods.

\subsubsection{THE MODEL.}

We shall thus extend the horizon of the firm to an additional period. Current period quantities will have a subindex 1, future period quantities a subindex 2 . To simplify consumer and government will be taken the same as in the previous model : the household will have a supply of labor $\ell_{0}$ and a çonsumption function :

$$
\tilde{c}_{1}=c\left(y_{1}, \bar{M}, p, \tau\right)
$$


$\mathrm{y}_{1}$ being now current period income.

Government will tax income at the rate $\tau$ and express an effective demand for goods $\tilde{g}$.

We now turn to the description of the firm.

\subsubsection{THE FIRM.}

The firm is assumed to have the same production function as above in the two periods:

$$
q_{1}=F\left(l_{1}\right) \quad q_{2}=F\left(l_{2}\right)
$$

We shall assume that goods not sold in the first period can be stored costlessly until the second period. Thus calling I the level of inventories, $y_{1}$ and $y_{2}$ the sales in the first and second period, we will have :

$$
\begin{array}{ll}
y_{1}+I=q_{1} & I \geq 0 \\
y_{2} \leq q_{2}+I &
\end{array}
$$

which can be also written :

$$
\begin{aligned}
& y_{1} \leq q_{1} \\
& y_{1}+y_{2} \leq q_{1}+q_{2}
\end{aligned}
$$

The firm must form some expectations about future prices and quantity constraints. As we want to concentrate on only one expectational variable, we shall assume: 
- that future price and wage are expected to be the same as the current ones ( $p$ and $w)$,

- that no constraint on the labor market is expected,

- that a constraint $\bar{y}_{2}$ on the future goods market is expected. This constraint, which represents the expected level of demand, will be the expectation variable we shall use as a parameter.

'The firm is assumed to maximize the sum of current and expected profits (1), i.e. to maximize :

$$
\pi_{1}+\pi_{2}=p y_{1}-w l_{1}+p y_{2}-w l_{2}
$$

\subsubsection{THE EFFECTIVE DEMAND FOR LABOR.}

The form of the effective demand for labor by the firm will be quite important in determining whether one is in a situation of Keynesian or classical unemployment. The effective demand for labor is obtained through maximization of the objective function of the firm, subject to quantity constraints on markets other than the current labor market, i.e. it is given by :

$$
\begin{aligned}
& \text { Maximize } p y_{1}-w l_{1}+p y_{2}-w l_{2} \quad \text { s.t. } \\
& \left\{\begin{array}{l}
q_{1}=F\left(l_{1}\right) \quad q_{2}=F\left(l_{2}\right) \\
y_{1} \leq q_{1} \\
y_{1}+y_{2} \leq q_{1}+q_{2} \\
y_{1} \leq \bar{y}_{1} \\
y_{2} \leq \bar{y}_{2}
\end{array}\right.
\end{aligned}
$$

(1) The assumptions of a zero rate of discount, as well as a zero of depreciation of inventories are only made to yield simple calculations. 
yielding

$$
\tilde{l}_{1}^{d}=\min \left\{F^{\prime-1}\left(\frac{w}{p}\right), F^{-1}\left[\max \left(\bar{y}_{1}, \frac{\bar{y}_{1}+\bar{y}_{2}}{2}\right)\right]\right\}
$$

We recognize immediately a "Classical" and a "Keynesian" demand. The last one now depends not only on current effective demand $\bar{y}_{1}$, but also on expected future demand $\bar{y}_{2}$. We see that in the event of a binding current constraint on sales $\bar{y}_{1}$, the producer may want to produce beyond $\bar{y}_{1}$, piling up inventories for later sales. We can remark also that for the demand for labor to have the Keynesian form, both constraints $\bar{y}_{1}$ and $\bar{y}_{2}$ must be binding. 


\section{4. - THE DIFFERENT REGIONS.}

We shall now determine the level of employment and income, according to the pattern of excess demands or supply on the labor and goods markets. Whenever unemployment is present, we shall pay particular attention to its nature ('Llassical" or "Keynesian").

\subsubsection{GENERAL EXCESS SUPPLY.}

In this case, national income will be equal to the aggregate demand for goods :

$$
y_{1}=\tilde{c}+\tilde{g}=c\left(y_{1}, \vec{M}, P, \tau\right)+\tilde{g}
$$

which yields the equilibrium income :

$$
y_{1}^{*}=y_{k}(\bar{M}, p, \tilde{g}, \tau]
$$

National income is thus given by a multiplier formula, as in the model above. Employment $e_{1}^{*}$ is equal to the effective demand for labor, which yields, since $\bar{y}_{1}=y_{k}$ :

$$
\ell_{1}=\min \left\{F^{-1}\left(\frac{w}{p}\right), F^{-1}\left[\max \left(y_{k}, \frac{y_{k}+\bar{y}_{2}}{2}\right)\right]\right\}
$$

We see that this expression differs somewhat from the expression in the stockless model, i.e. $F^{-1}\left(y_{k}\right)$ :

- First, for quite "optimistic" $\bar{y}_{2}$, employment may be pushed to $F{ }^{-1}(W / p)$. Unemployment is thus classical, and Keynesian measures will have no effect on employment, even though we are in the region of general excess supply. 
- Second, even when employment has a "Keynesian"value, it may be bigger than the employment necessary to produce for current demand. In such a case the employment multiplier will be also smaller as part of the unsold goods is "absorbed" into inventories.

To summarize, the excess supply region will be separated in two subregions ; in both income will be given by a Keynesian multiplier formula. However in one (noted $K$ ) unemployment will be Keynesian while in the other (noted CK) it will be classical.

\subsubsection{EXCESS SUPPLY OF GOODS, EXCESS DEMAND FOR LABOR.}

Since there is excess supply of goods, the level of income is again given through a multiplier formula :

$$
y_{1}^{*}=y_{k}
$$

Since there is excess demand for labor, employment is determined by the inelastic supply:

$$
l_{1}^{*}=\ell_{0}
$$

Note that this situation did not exist, except as a limiting case, in the stockless model. For it to happen here, we must have an effective demand for labor higher than $\ell_{0}$, enven though current demand $y_{k}$ is smaller than $y_{0}$. This implies thus quite optimistic expectations (specifically $\bar{y}_{2}>y_{0}$ ), so that the firm will be led to hire all labor force, and pile up inventories for future sales. We shall denote this region FK since there is full employment, with income determined in a Keynesian manner. 
2.4.3. EXCESS DEMAND FOR GOODS, EXCESS SUPPLY OF LABOR.

With excess demand for goods, the demand for labor has the classical form, and employment is equal to this demand

$$
l_{1}^{*}=F^{,-1}\left(\frac{w}{p}\right)
$$

Sales of goods are equal to production :

$$
y_{1}^{*}=F\left[F^{\prime-1}\left(\frac{w}{p}\right)\right]
$$

This region is thus characterized by classical unemployment, and will be denoted $C$.

\subsubsection{GENERAL EXCESS DEMAND.}

There employment is equal to the inelastic supply:

$$
\ell_{1}^{*}=\ell_{0}
$$

Sales are blocked by full employment production :

$$
y_{1}^{*}=y_{0}
$$

We shall denote this region $R$ (for repressed inflation) as in the stockless model. 


\section{5. - THE COMPIETE PICTURE.}

There remains now to determine for which values of the parameters $p, w, \bar{M}, \tilde{g}, \tau, \bar{y}_{2}$ we shall have each of the above possibilities. We know that current employment $e_{1}^{*}$, sales $y_{1}^{*}$ and production $q_{1}^{*}$ will be solution of the optimization program of the firm taking into account all quantity constraints, i.e. they will be solution of :

$$
\begin{aligned}
& \text { Max } p y_{1}-w l_{1}+p y_{2}-w l_{2} \\
& y_{1} \leq q_{1} \\
& y_{1}+y_{2} \leq q_{1}+q_{2}=F\left(l_{2}\right) \\
& y_{1} \leq \bar{y}_{1}=\tilde{c}_{1}+\tilde{g} \\
& y_{2} \leq \bar{y}_{2} \\
& \ell_{1} \leq l_{0}
\end{aligned}
$$

The constraint $y_{1} \leq \vec{y}_{1}$ can be, as above, replaced by $y_{1} \leq y_{k}(M, p, \tilde{g}, \tau)$ and the program then yields :

$$
\begin{aligned}
& y_{1}^{*}=\min \left\{y_{0}, F\left[F^{-1}\left(\frac{w}{p}\right)\right], y_{k}\right\} \\
& q_{1}^{*}=\min \left\{y_{0}, F\left[F^{-1}\left(\frac{w}{p}\right)\right], \max \left[y_{k}, \frac{y_{k}+\bar{y}_{2}}{2}\right]\right\} \\
& e_{1}^{*}=\min \left\{l_{0}, F^{\prime-1}\left(\frac{w}{p}\right), F^{-1}\left[\max \left(y_{k}, \frac{y_{k}+\bar{y}_{2}}{2}\right)\right]\right\}
\end{aligned}
$$

We shall, as for the stockless model, draw the different regions in a $\left(\frac{w}{p}, y_{k}\right)$ plane, for different values of $\bar{y}_{2}$ (Figure 4 ). 


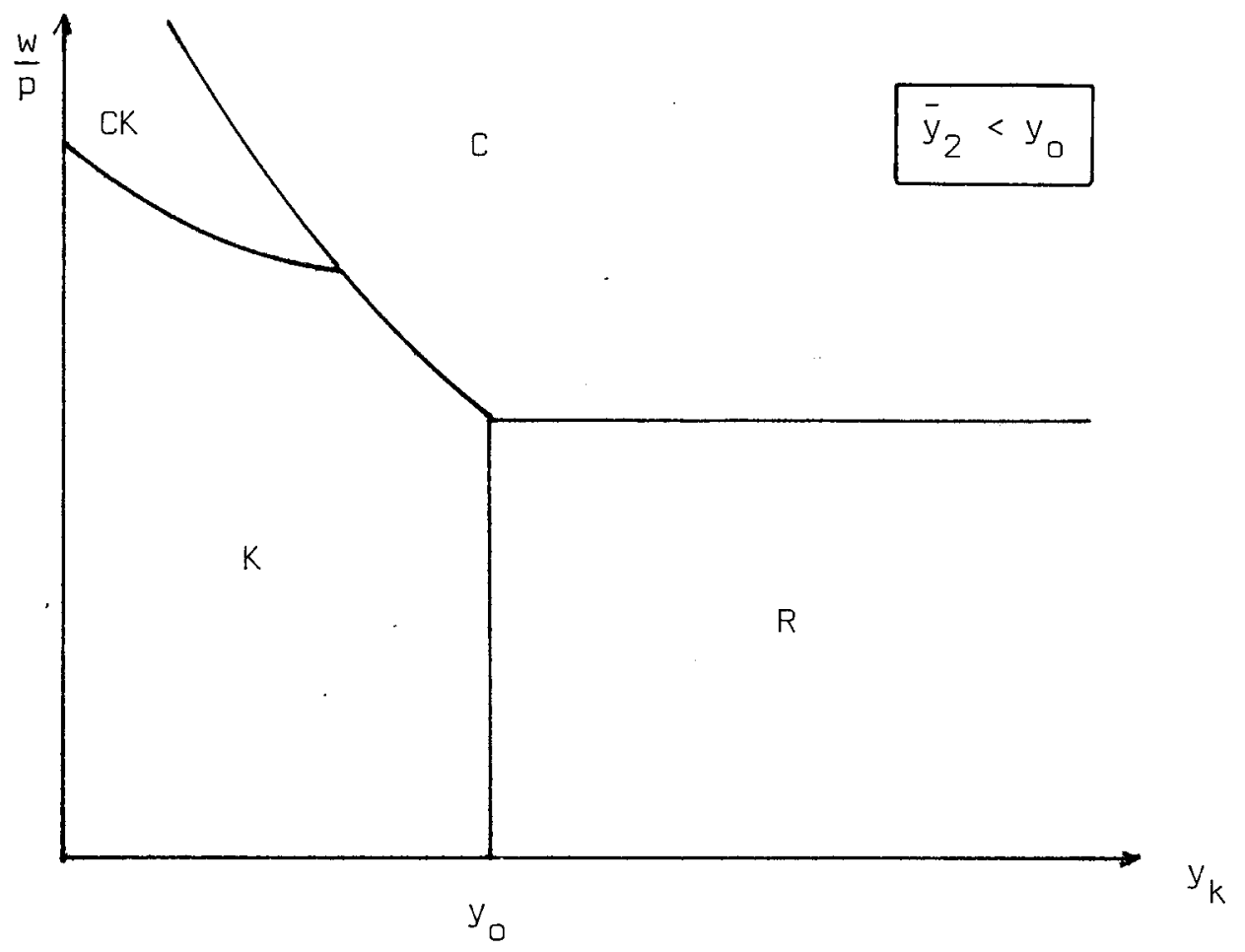

Fig. 4.a

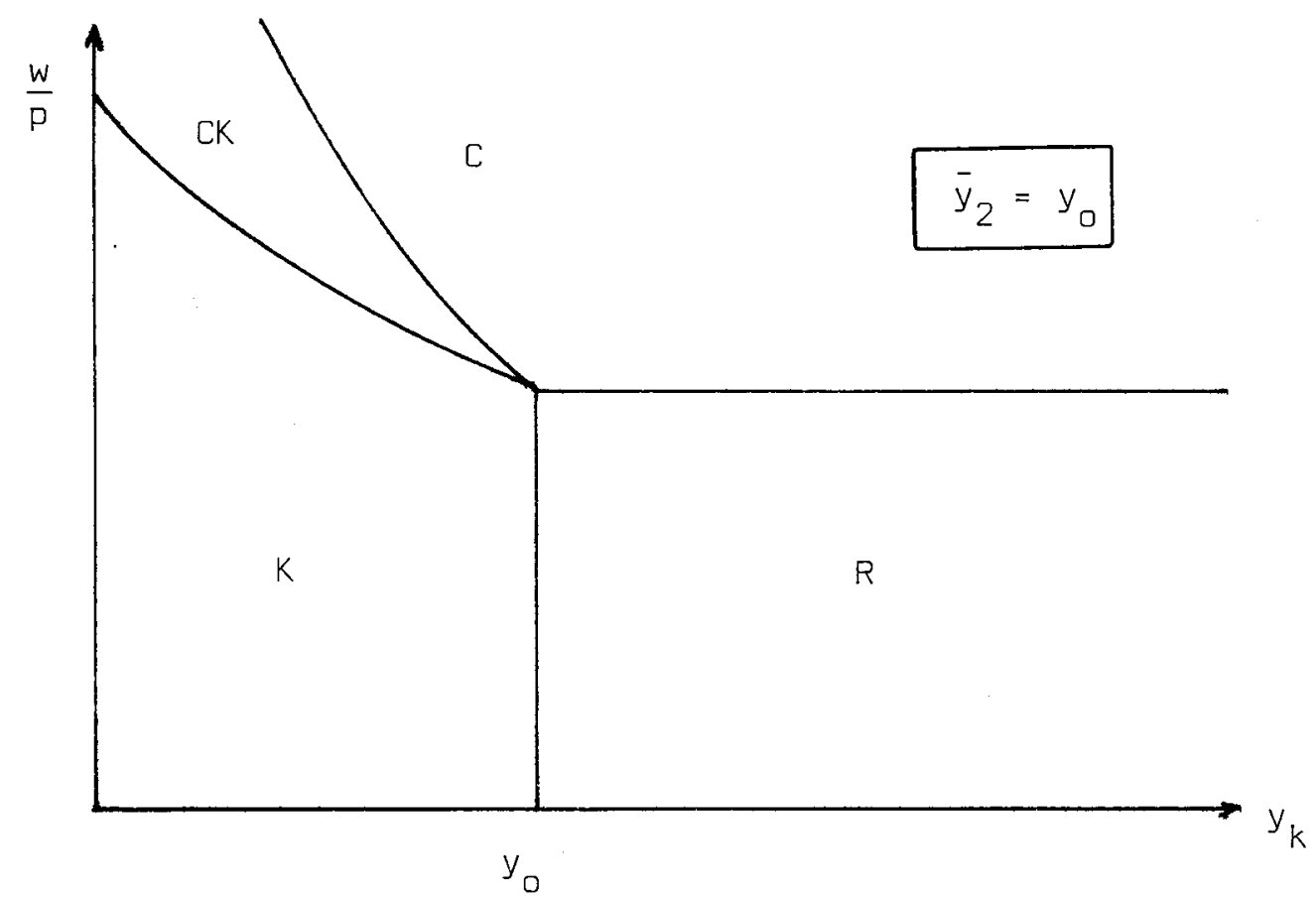

Fig. 4.6 


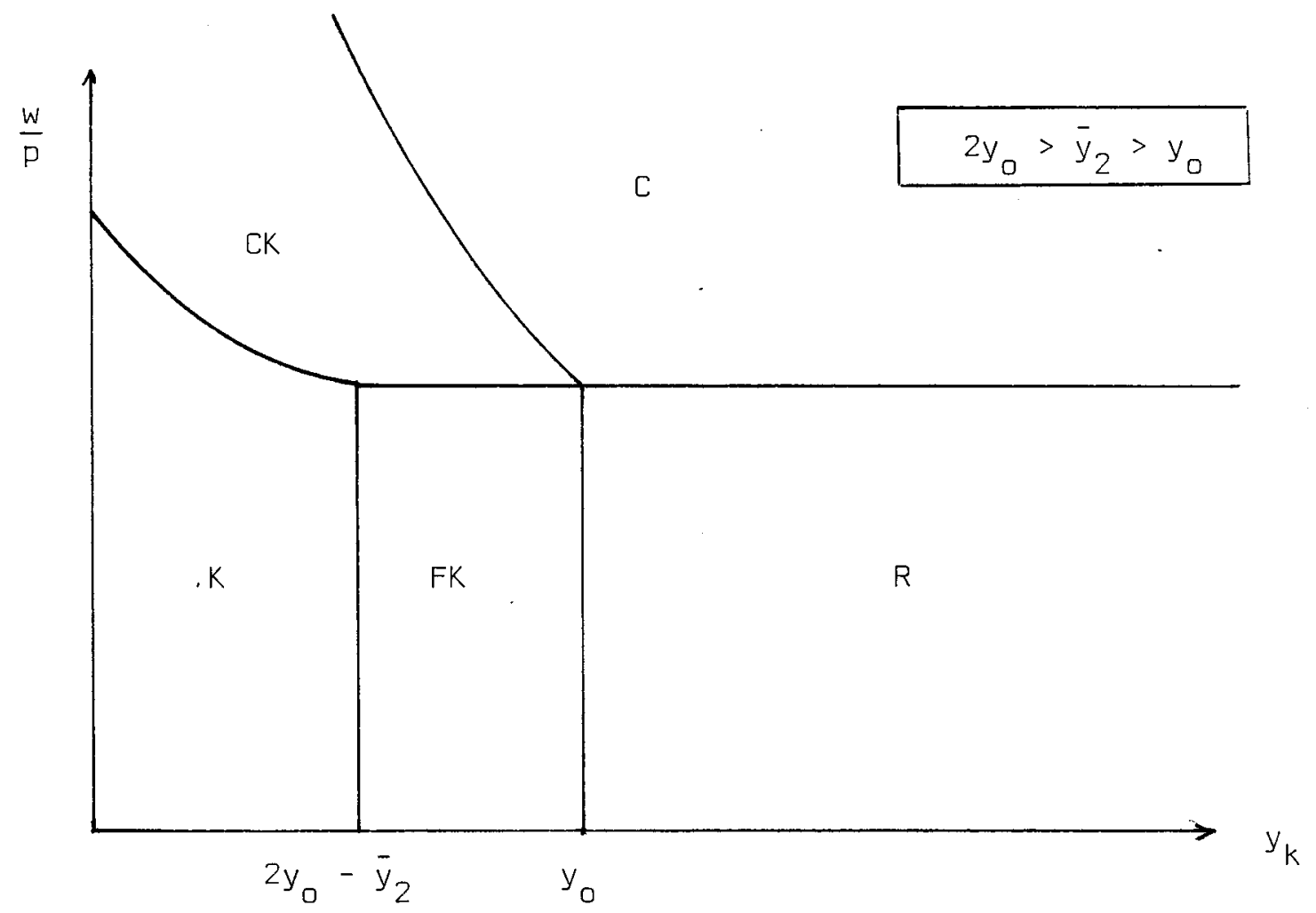

Fig. 4.c

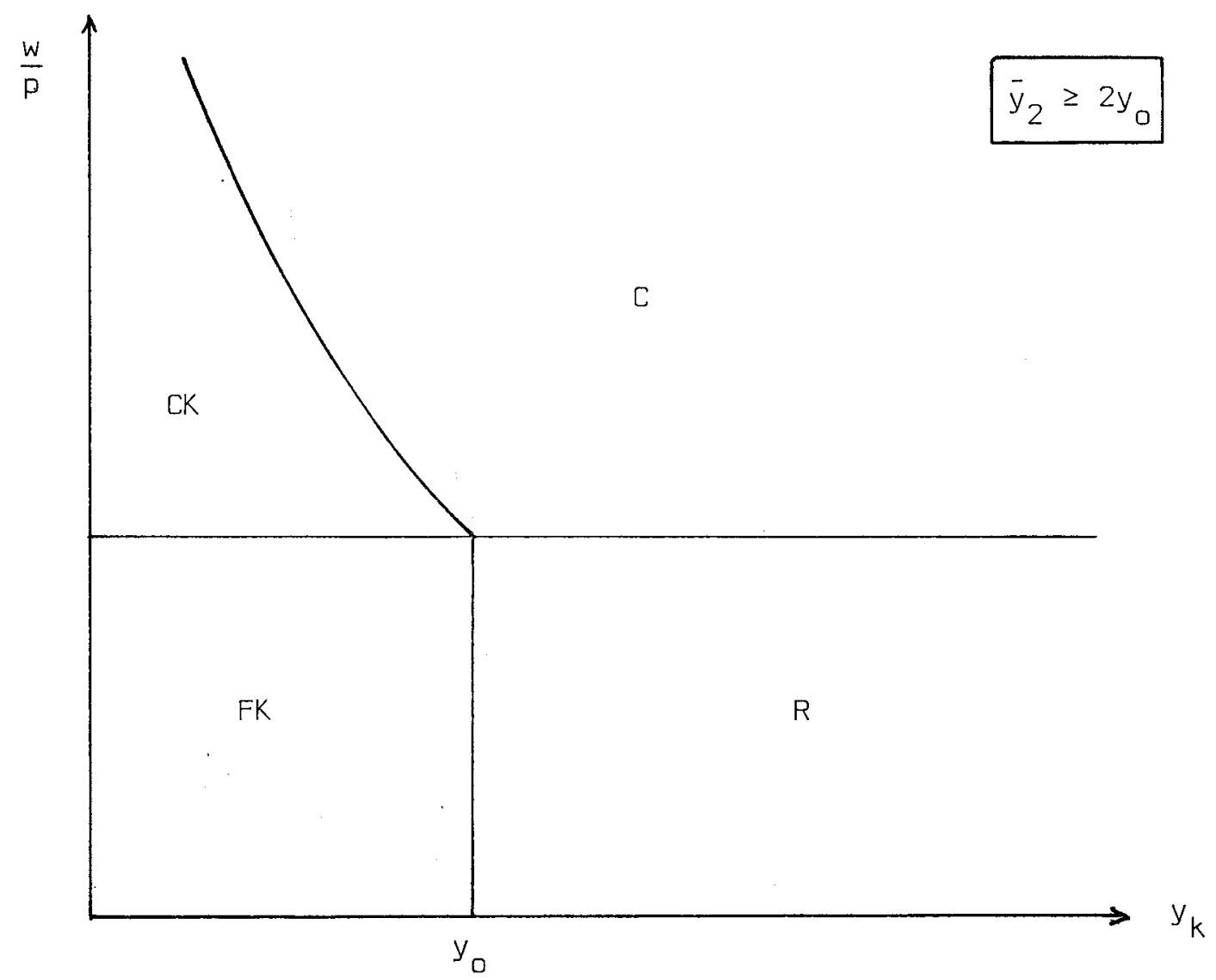

Fig. 4.d 
ABRAMOWITZ M. (Ed.) (1959) The Allocation of Economic Resources, Stanford University Press, Stanford.

ARROW K.J. (1959) "Towards a Theory of Price Adjustment" in Abramowitz Ed. $(1959)$.

ARROW K.J. and HAHN F.H. (1971) General Competitive Analysis. San Francisco : Holden-Day, 1971.

BARRO R.J. and GROSSMAN H.I. (1971) "A General Disequilibrium Model of Income and Employment", American Economic Review, 61, pp. 82-93.

BARRD R.J. and GROSSMAN H.I. (1974) "Suppressed Inflation and the. Supply Multiplier", Review of Economic Studies, 41, pp. 87-104.

BARRO R.J. and GROSSMAN H.I. (1976) Money, Employment and Inflation. Cambridge University Press, Cambridge, 1976.

BENASSY J.P. (1973) "Disequilibrium Theory", Unpublished Ph.D. Dissertation, University of California, Berkeley, Hungarian Translation in Szygma (1974).

BENASSY J.P. (1974) "Théorie Néokeynésienne du Déséquilibre dans une Economie Monétaire", Cahiers du Séminaire d'Econométrie", No 17, pp. 81-113.

BENASSY J.P. (1975a) "Disequilibrium Exchange in Barter and Monetary Economies", Economic Inquiry, 13, pp. 131-156.

BENASSY J.P. (1975b) "Neo-Keynesian Disequilibrium Theory in a Monetary Economy", Review of Economic Studies, 42, pp.503-523. 
BENASSY J.P. (1976a) "The Disequilibrium Approach to Monopolistic Price Setting and General Monopolistic Equilibrium", Review of Economic Studies, 43, pp. 69-81.

BENASSY J.P. (1977) "On Quantity Signals and the Foundations of Effective Demand Theory", The Scandinavian Journal of Economics, 79, pp. 147-168.

BENASSY J.P. (1978a) "A Neokeynesian Model of Price and Quantity Determination in Disequilibrium" in Equilibrium and Disequilibrium in Economic Theory, (G. Schwödiauer Ed.) D. Reidel Publishing Company, Boston. Proceedings of a Conference in Vienna, June 1974.

BENASSY J.P. (1978b) "Cost and Demand Inflation Revisited : A Neokeynesian Approach", Economie Appliquée, 31, pp. 113-133.

BOHM V. and LEVINE J.P. (1979) "Temporary Equilibria with Quantity Rationing", Review of Economic Studies, 46, pp. 361-377.

BUSHAW D.W. and CLOWER R. (1957) Introduction to Mathematical Economics, Richard D. Irwin, Homewood, Illinois.

CLOWER R.W. (1965) "The Keynesian Counterrevolution : A Theoretical Appraisal", in The Theory of Interest Rates, ed. by F.H. HAHN and F.P.R. BRECHLING. MacMilian, Londan.

CLOWER R.W. (1967) "A Reconsideration of the Microfoundations of Monetary Theory", Western Economic Journal, 6, pp. 1-9.

DEBREU G. (1959) Theory of Value, Wiley, New York.

DIXIT A. (1978) "The Balance of Payments in a Model of Temporary Equilibrium with Rationing", Review of Economic Studies, 45, pp. 393-404.

DRAZEN A. (1980) "Recent Developments in Macroeconomic Disequilibrium Theory", Econometrica, 48, pp. 283-306. 
DREZE J. (1975) "Existence of an Equilibrium under Price Rigidity and Quantity Rationing", International Economic Review, 16, pp. 301-320.

GLUSTOFF E. (1968) "On the Existence of a Keynesian Equilibrium", Review of Economic Studies, 35, pp. 327-334.

GRANDMONT J.M. (1974) "On the Short Run Equilibrium in a Monetary Economy", in Allocation Under Uncertainty, Equilibrium, and Optimality, ed. by J. Drèze. London : Macmillan, 1974.

GRANDMONT J.M. (1977) "Temporary General Equilibrium Theory", Econometrica, 45, pp. 535-572.

GRANDMONT J.M. and LAROQUE G. (1976) "On Keynesian Temporary Equilibria", Review of Economic Studies, 43, pp. 53-67.

GRANDMONT J.M., LAROQUE G. and YOUNES Y. (1978) "Equilibrium with Quantity Rationing and Recontracting", Journal of Economic Theory, 19, pp. 84-102.

HAHN F.H. (1978) "On Non-Walrasian Equilibria", Review of Economic Studies, 45, pp. 1-17.

HAHN F.H. and NEGISHI T. (1962) "A Theorem of Non Tatonnement Stability", Econometrica, 30, pp. 463-469.

HANSEN Bent (1951) A Study in the Theory of Inflation, Allen and Unwim, London.

HELLER W.P. and STARR R.M. (1979) "Unemployment Equilibrium with Myopic Complete Information", Review of Economic Studies, 46, pp. 339-359.

HICKS J. (1965) Capital and Growth. Oxford University Press, Oxford.

HILDENBRAND K: and HILDENBRAND W. (1978) "On Keynesian Equilibria with Unemployment and Quantity Rationing", Journal of Economic Theory, 18, pp. 255-277 
KEYNES J.M. (1936) The General Theory of Money, Interest and Employment, Harcourt Brace, New York.

LEIJONHUFVUD A. (1968) On Keynesian Economics and the Economics of Keynes. Oxford University Press, Oxford.

MALINVAUD E. (1977) The Theory of Unemployment Reconsidered. Basil Blackwell, oxford.

MALINVAUD E. and YOUNES Y. (1978) "Une Nouvelle Formulation Générale pour l'Etude des Fondements Microéconomiques de la Macroéconomie", Cahiers du Séminaire d'Econométrie.

MICHEL P. (1980) "Keynesian Equilibrium and Fix-price Equilibria", Warwick Discussion Paper, February 1980.

MUELBAUER J. and PORTES R. (1978) "Macroeconomic Models with Quantity Rationing", Economic Journal, 88, pp. 788-821.

NEARY P. and STIGLITZ J. (1980) "Towards a Reconstruction of Keynesian Economics: Expectations and Constrained Equilibria",

NEGISHI T. (1961) "Monopolistic Competition and General Equilibrium", Review of Economic Studies, 28, pp. 196-201.

NEGISHI T. (1972) General Equilibrium Theory and International Trade, North Holland, Amsterdam.

NEGISHI T. (1978) "Existence of an Under Employment Equilibrium", in Equilibrium and Disequilibrium in Economic Theory, ed. by. G. Schwödiauer, Boston : D. Reidel Pub. Co., 1978.

NEGISHI T. (1979) Microeconomic Foundations of Keynesian Macroeconomics, North-Holland, Amsterdam. 
PATINKIN D. (1956) Money, Interest and Prices, (2nd ed. 1965), Harper and Row, New York.

SOLOW R.M. and STIGLITZ J. (1968) "Output, Employment and Wages in the Short Run", Quaterly Journal of Economics, November 1968.

YOUNES Y. (1970) "Sur les Notions d'Equilibre et de Déséquilibre Utilisées dans les Modèles décrivant I'Evolution d'une Economie Capitaliste", CEPREMAP.

YOUNES Y. (1975) "On the Role of Money in the Process of Exchange and the Existence of a Non-Walrasian Equilibrium", Review of Economic Studies, $\underline{42}$, pp. 489-501. 